\title{
Küttner's Tumour - Chronic Sclerosing Sialadenitis of the Submandibular Gland
}

\author{
CM Bowe ${ }^{1 *}$, C Wan ${ }^{2}$, T Walker ${ }^{3}$ and S Walsh ${ }^{4}$ \\ ${ }^{1}$ ST3 Trainee OMFS, St Richards Hospital, Western Sussex, Shire \\ ${ }^{2}$ Dental Core Trainee in OMFS, St Richards Hospital, Western Sussex, Shire \\ ${ }^{3}$ Consultant Pathologist, St Richards Hospital, Western Sussex, Shire \\ ${ }^{4}$ Consultant Oral \& Maxillofacial Surgeon, St Richards Hospital, Western Sussex, Shire
}

Received: November 07, 2017; Published: November 13, 2017

*Corresponding author: Conor M Bowe, Oral \& Maxillofacial Surgery Department, St Richards Hospital, Chichester, Western Sussex, Shire

\section{Introduction}

Chronic sclerosing sialadenitis, originally described by $\mathrm{H}$. Küttner in 1896, is a rare cause of salivary gland enlargement [1]. Its clinical and radiographic presentations can mimic other conditions such as, lymphoma or infectious causes and can only be correctly diagnosed following removal of the gland. This "Küttner's Tumour" is now classified as an IgG4 related disease, with characteristic dense infiltrate of immunoglobulin (Ig) G4positive plasma cells. However, the exact aetiology of IgG4 related disease remains unknown with no known role of the IgG4 molecule itself [2]. Other IgG 4 related diseases include Riedel's thyroiditis, Mikulicz's disease and idiopathic retroperitoneal fibrosis [3]. This case demonstrates the diagnostic difficulty of this presentation, with multiple differential diagnoses that cannot be excluded until the final histopathological examination.

\section{Case Report}

The patient was a 63-year-old man who presented with bilateral submandibular swelling, which were present for four months. Physical examination showed firm, non-tender enlarged submandibular glands. The laboratory values showed a normal leukocyte count (10.6 x 10\% $/ \mathrm{L})$, haemoglobin level $14.2 \mathrm{~g} / \mathrm{dL})$, and platelet count $\left(292 \times 10^{9} / \mathrm{L}\right)$. Nasoendoscopy examination to the level of the vocal cords was unremarkable. Ultrasound showed the submandibular glands contained a number of hypoechoic nodules which were well defined with attenuated echogenic strands internally. Fine needle aspiration cytology showed a mixed population of lymphoid cells. Contrast-enhanced computerised tomography scan revealed bilateral asymmetrical enlargement of right and left submandibular glands (Figure 1). No sialolithiasis was found. There was no significant cervical lymphadenopathy. As the diagnosis of lymphoma could not be excluded a decision was made to remove the right submandibular gland. Final pathology revealed the submandibular gland measured 55x38x25 mm. Histologically the lesion was composed of well-defined areas showing stromal fibrosis associated with acinar atrophy, florid chronic inflammation that includes conspicuous germinal centres, but also prominent numbers of interstitial plasma cells and vascular changes (Figures $2 \& 3)$.

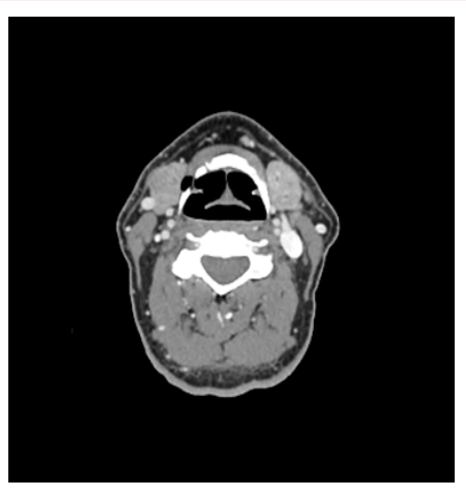

Figure 1: Head and neck Ct study image showing bilateral enlargement of sub mandibular glands measuring $3.3 \mathrm{~cm}$ $x 2.5 \mathrm{~cm}$ right and $3 \mathrm{~cm} \times 2.2 \mathrm{~cm}$ left.

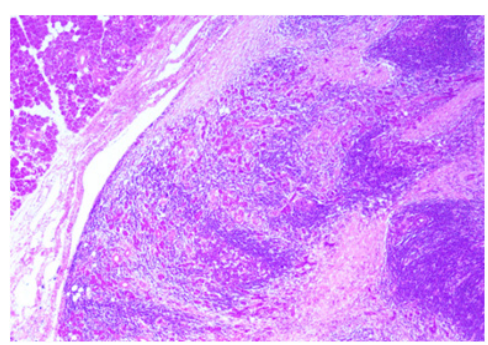

Figure 2: $[\mathrm{H}+\mathrm{E} \times 10]$ The low power slide shows normal salivary gland in the upper left corner of the slide and shows a very well demarcated lesion of chronic sclerasingsialadenitis. 


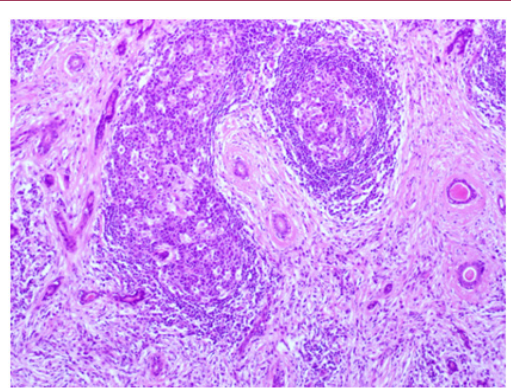

Figure 3: $[\mathrm{H}+\mathrm{E} \times 20]$ The high power view shows atrophic acini, stromal fibrosis, and lymphoid aggregates with germinal centers.

\section{Discussion}

Chronic sclerosing sialadenitis (Küttner's tumour) is a nonneoplastic, chronic inflammatory disease of the submandibular gland first described by Küttner in 1896 [1]. A predominance of male sex has been recognised in the sixth to eighth decades [4]. Two factors appear important in the aetiology of Küttner's tumour: an initial disturbance in saliva flow causing an obstructive sialadenitis and an immune reaction of the salivary duct system causing an obstructive progressive sialadenitis. Chronic sclerosing sialadenitis has been classified into four histological stages depending on the degree of inflammation;

a. Stage 1: focal sialadenitis;

b. Stage 2: diffuse lymphocytic sialadenitis with salivary gland fibrosis;

c. Stage 3: chronic sclerosing sialadenitis with salivary gland sclerosis;

d. Stage 4: chronic progressive sialadenitis with salivary gland cirrhosis [4];

Histologically, the disease is characterised by acinar atrophy, dense lymphocytic infiltration and fibrosis $[5,6]$.

Recently, more than $90 \%$ of cases of Küttner's tumour has been regarded as an immunoglobulin G4 (IgG4) related idiopathic sclerosing lesion [3,7]. IgG 4 constitutes only 3-6 \% of the total IgG fraction in the plasma of healthy patients and is the smallest component among the IgG subclasses and its biologic function remains uncertain. IgG 4 related sclerosing disease has been identified in a wide variety of organs, including pancreas, biliary tree, liver, gallbladder, lacrimal gland, salivary gland, kidney, lung pleura and lymph nodes [8].Currently, the histologic diagnosis of IgG4 related disease is based primarily on IgG4 positive to IgG containing cell ratio of $>50 \%$ and the number of IgG4 positive cells per high powered field (30) [6].

Elevated serum IgG4 level and marked improvement with steroid therapy are other common diagnostic features [2]. It is important to distinguish between chronic sclerosing sialadenitis and sialolithiasis-associated sialadenitis as the treatment is markedly different. Chronic sclerosing sialadenitis shows a dense chronic inflammatory infiltrate composed of fibroblasts, lymphocytes and plasma cells. This is differentiated from sialolithiasis-associated sialadenitis by an interlobular fibrosis with less cellularity. However in up to $40 \%$ of cases of chronic sclerosing sialadenitis, a sialolith occurs simultaneously [4]. IgG4 related sclerosing disease has been shown to have a good response to steroid treatment with full remission rates of $90 \%$ with medical therapy alone [2]. However most commonly chronic sclerosing sialadenitis will be surgically excised and diagnosed by the histopathologist as it can mimic submandibular gland malignancy [8]. Prognosis is very good as these are benign lesions that do not tend to recur [9].

\section{References}

1. Küttner H (1896) Uber entzundicheTumoren der Submanxillarspeicheldruse. Bruns Bietr Klin Chir. 15: 815-34.

2. Mulholland G, Jeffrey C, Satija P, Cote D (2015) Immunoglobulin G4 related diseases in the head and neck: a systematic review. J Otolaryngol Head Neck Surg 2015 20: 44:24.

3. Umehara H, Okazaki K, Masaki Y, Kawano M, Yamamoto M, et al. (2012) A novel clinical entity, IgG4 - related disease (IgG4RD): general concept and details. Mod Rheumatol 22(1): 1-14.

4. Seifert G, Donath K (1977) [On the pathogenesis of the Küttner tumor of the submandibular gland - Analysis of 349 cases with chronic sialadenitis of the submandibular (authors transl)]. HNO 25(3): 81-92.

5. Takano K, Yamamoto $M$, Takahashi H, Shinomura $Y$, Imai $K$, et al. (2010) Clinicopathological similarities between Mikulicz disease and Kuttnertumor. Am J Otolaryngol 31: 429-434.

6. Stone JH, Zen Y, Desphpande V (2012) IgG4 - related disease. N Eng J Med 366(6): 539-551.

7. Wei TW, Lien CF, Hsu TY, He HL (2015) Chronic sclerosingsialadenitis of the submandibular gland: an entity of IgG4- related sclerosing disease. Int J ClinExpPathol 8: 8628-8631.

8. Cheuk W, Chan JK (2012) Lymphadenopathy of IgG4-related disease: an under diagnosed and over diagnosed entity. SeminDiagn Pathol 29(4): 226-234.

9. Furukawa S, Moriyama M, Kawano S, Tanaka A, Maehara T, et al. (2015) Clinical relevance of Küttner tumour and IgG4-related dacryoadenitis and sialoadenitis. Oral diseases 21: 257-262.

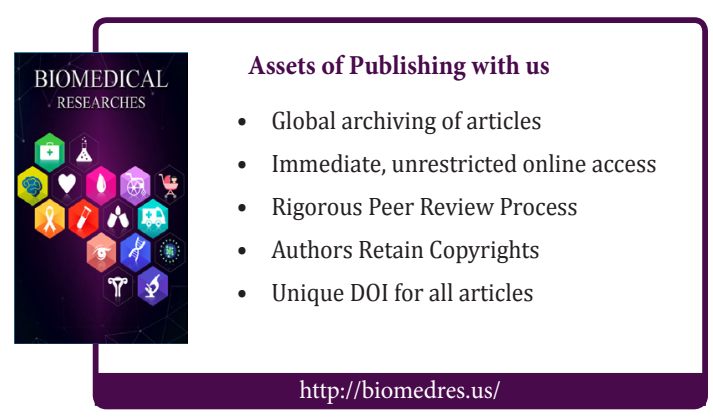

